\title{
Large Osteolytic Skull Tumor Presenting as a Small Subcutaneous Scalp Lesion
}

\author{
John E. Sutherland, MD, Nader S. Dahdaleh, MD, Jeremy D. W. Greenlee, MD, \\ Patricia A. Kirby, MD, and Michael D. Sargent, DO
}

Subcutaneous nodules of the scalp are common and usually benign. We describe a case that presented as a probable inclusion cyst or lipoma of the scalp that was discovered to be a benign osteolytic fibrohistiocytic lesion of the frontoparietal skull. This ultimately was successfully treated by neurosurgery with a craniectomy, tumor excision, and reconstructive cranioplasty. ( $\mathrm{J}$ Am Board Fam Med 2011;24: 763-767.)

Keywords: Bone Tumor, Case Report, Giant Cell Tumor, Scalp Lesion, Skull Tumor

Tumors of the skull are uncommon, with estimates varying between $1 \%$ to $4 \%$ of all bone tumors. ${ }^{1-3}$ They most commonly present as an enlarging soft or hard mass over the skull with or without some local tenderness. The differential diagnosis is broad and includes both benign and malignant lesions. Most lesions are radiolucent and osteolytic and are more common in young adults. Imaging studies are essential in the workup, and a biopsy is of paramount importance in establishing a diagnosis and treatment options.

\section{Case Reports}

A 58-year-old woman presented to the family practice clinic with a lump on her right anterior scalp; it had been present for 6 months but began annoying her once her hair stylist called attention to it. The examining physician described it as a $3-\mathrm{cm}$, illdefined subcutaneous cystic lesion and referred the patient to the procedure clinic for excision of a probable inclusion cyst. At the time of the proce-

This article was externally peer reviewed.

Submitted 31 December 2010; revised 29 March 2011; accepted 6 April 2011.

From the Northwest Iowa Family Practice Residency Program, Waterloo, IA (JES, MS); the Department of Neurosurgery (NSD, JDWG) and the Department of Pathology (PAK), University of Iowa Hospitals and Clinics, Iowa City, IA.

Funding: none.

Conflict of interest: none declared.

Corresponding author: John E. Sutherland, Northeast Iowa Family Practice Residency Program, 2055 Kimball Avenue, Waterloo, IA 50702 (E-mail: JSutherl@neimef.org). dure the lump did not feel as circumscribed as an inclusion cyst, and was thought to be more likely a lipoma because it seemed to be mobile. The adjacent skull felt normal. After incision through the scalp, the lesion was found to have a shiny, grayish exterior. In the process of dissection, the lesion was incised and chunks of whitish-yellow cheesy substance were extruded. When attempting to define the inferior portion of the lesion, the irregular edge of a 2.5- to 3-cm complete bony defect of the skull was palpable. The remaining subcutaneous abnormal tissue was removed, as was a component of the lesion's wall. The wound was closed. The excised material was sent to pathology. The diagnosis was a benign fibrohistiocytic lesion with scattered giant cells. Skull radiographs revealed a lytic lesion of the right frontal bone without sclerosis measuring $6 \times$ $5.5 \times 4.4 \mathrm{~cm}$ (Figure 1).

The patient was referred to the neurosurgery department at the University of Iowa. A magnetic resonance imaging scan of the brain was performed to delineate the extent of the lesion (Figure 2). There was extensive bony erosion with broadbased dural thickening (Figure 2C). There was no brain involvement.

A right frontoparietal craniectomy was performed (Figure 3A). The tumor was attached to the underlying dura (Figure 3B). The subdural surface and underlying cortex were unremarkable (Figures $3 \mathrm{~B}$ and D). A synthetic duraplasty and custom contoured polymethylmethacrylate cranioplasty were performed. The patient's postoperative course was 
Figure 1. Anteroposterior and lateral skull radiographs showing the lytic lesion involving the right frontoparietal bones.

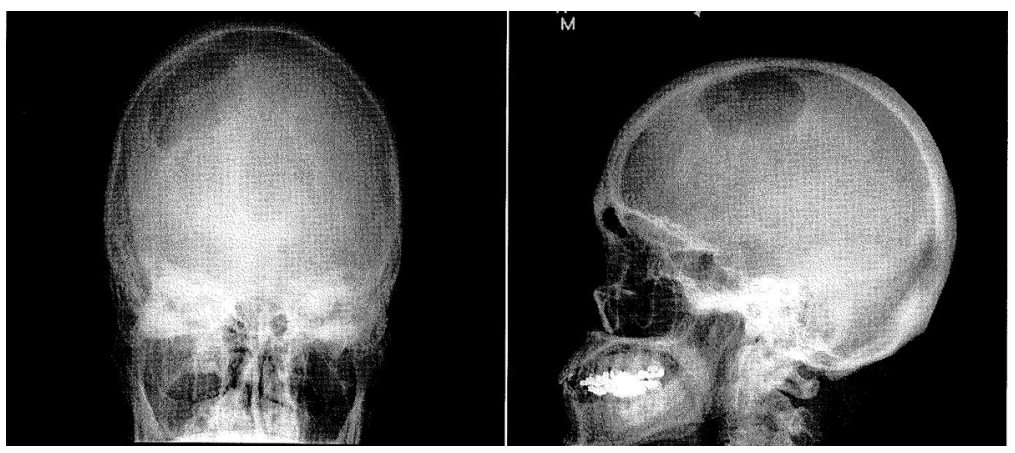

unremarkable and she was discharged on postoperative day 2. Her immediate postoperative and 6-month follow-up magnetic resonance images show no residual disease (Figure 4).

The final pathology was a fibrohistiocytic lesion with giant cells (Figure 5). At the last office follow-up, the patient was asymptomatic and had a good cosmetic result. No adjuvant therapy is planned; however, serial brain magnetic resonance imaging will be conducted to exclude tumor recurrence.

\section{Discussion}

Our patient, a 58-year-old woman, was essentially healthy with well-controlled hypertension, hyperlipidemia, and intermittent asthma. Her referral to our procedure clinic was routine without anticipation of issues other than the excision of a benign subcutaneous lesion of her scalp.

The most common benign lesions of the scalp among adults are inclusion cysts and lipomas. Occasionally, these lesions have intraosseous and intracranial extension, ${ }^{4,5}$ especially if they are located in the vicinity of a skull suture. The patient did describe to the referring physician that she had felt an indentation of the skull beneath the lesion, which was not appreciated by the operating physician. At the beginning of the office procedure the lesion seemed to have completely benign features with no reported trauma, a late-life onset, nonsuture line association, was freely mobile, and had a rubbery, firm consistency. ${ }^{4}$ Therefore, a skull radiograph was not performed before the procedure. Once the radiographs were obtained, the osteolytic lesion was evident, and subsequent high-resolution imaging and definitive treatment was achieved.

Skull tumors represent a small component of overall bone tumors, and $81 \%$ were malignant in a large Mayo Clinic series. ${ }^{1}$ Common benign bone tumors include osteochondromas, giant cell tumors, aneurysmal bone cysts, osteoblastomas, fibrous dysplasia, fibromas, simple bone cysts, hemangiomas, intraosseous meningiomas, and eosinophilic granulomas. ${ }^{6-9}$ The first four have the potential to behave aggressively, and osteochondromas and giant cell tumors have the potential to recur ${ }^{7,9}$ or result in pul-

Figure 2. Sagittal (A), axial (B), and coronal (C) magnetic resonance imaging showing a homogeneously enhancing lesion arising from the right frontoparietal bone. Note the superior bulging of the mass into the subcutaneous soft tissue and the mass effect on the brain.

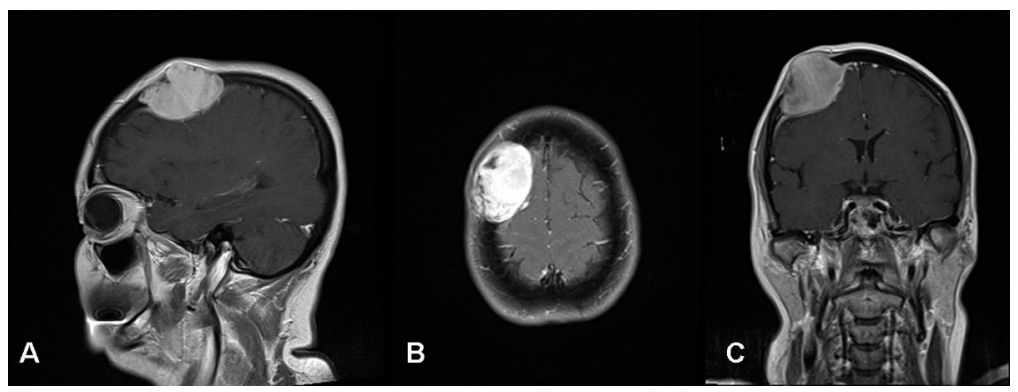


Figure 3. Composite operative picture depicting the skull lesion (A, arrow). The lesion was adherent to the dura matter (B, arrow). En bloc resection of the lesion, superior view (C), and inferior view (D) measuring $5.5 \times 5.5$ $\mathrm{cm}$. Macroscopic yellowish content of the lesion is demonstrated in subfigure (E). Polymethylmethacrylate cranioplasty was performed due to the bone involvement (F).
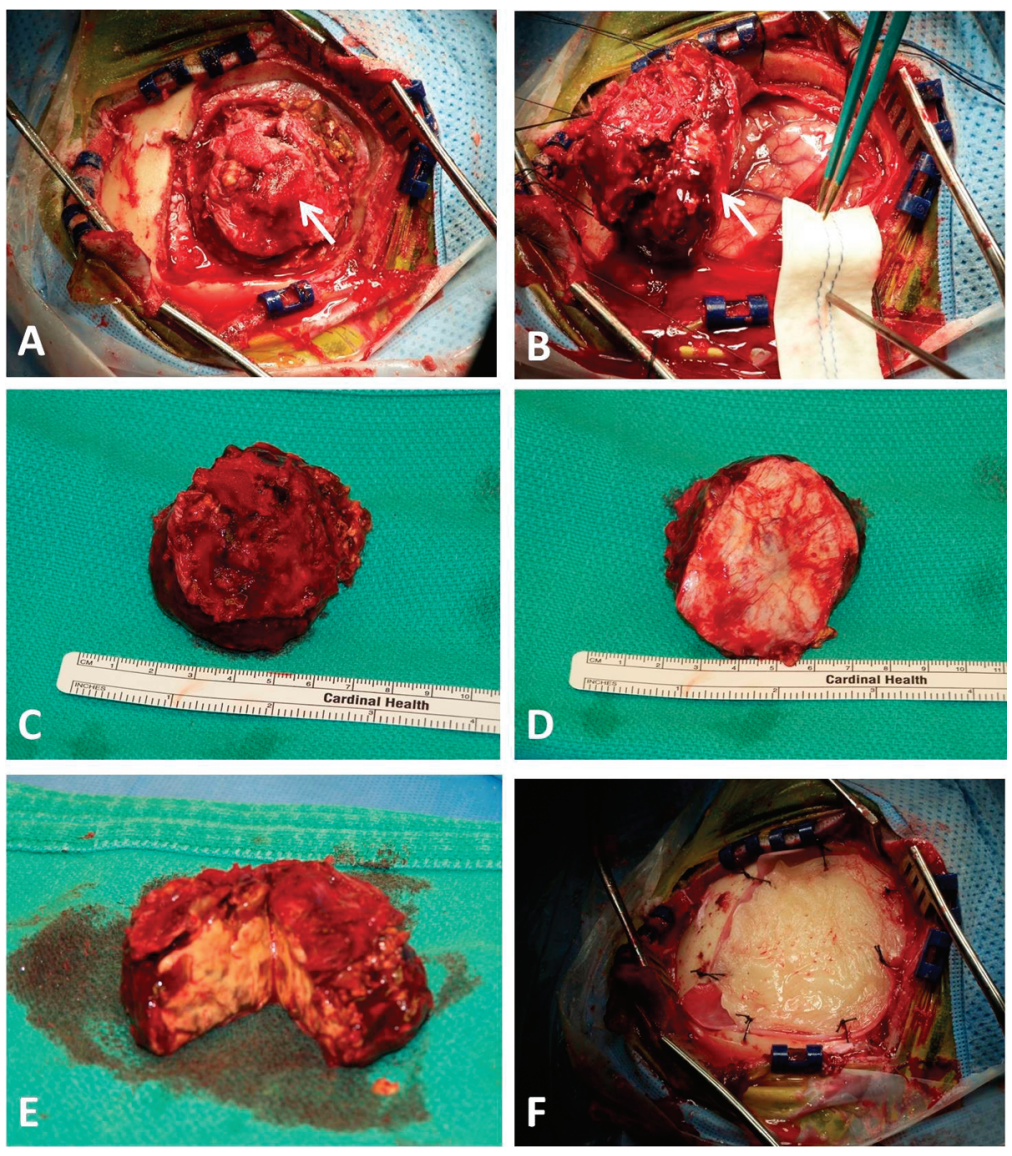

monary metastases. ${ }^{3,10,11}$ The more common primary malignant bone tumors of the skull include Ewing's sarcoma, osteosarcoma, leukemia, and multiple myeloma. Metastatic tumors are far more common and must be considered during the differential diagnosis of any bone lesion in a patient older than 40 years of

age. ${ }^{12}$ Skull metastases may be the initial manifestation of a malignancy elsewhere. ${ }^{13}$

A review of the literature revealed that fibrohistiocytic lesions with giant cells can be either predominantly histiocytic tumors or giant cell tumors. Giant cell tumors account for $4 \%$ to $5 \%$ of all

Figure 4. Sagittal (A), axial (B), and coronal (C) postoperative magnetic resonance imaging showing complete resection of the lesion.

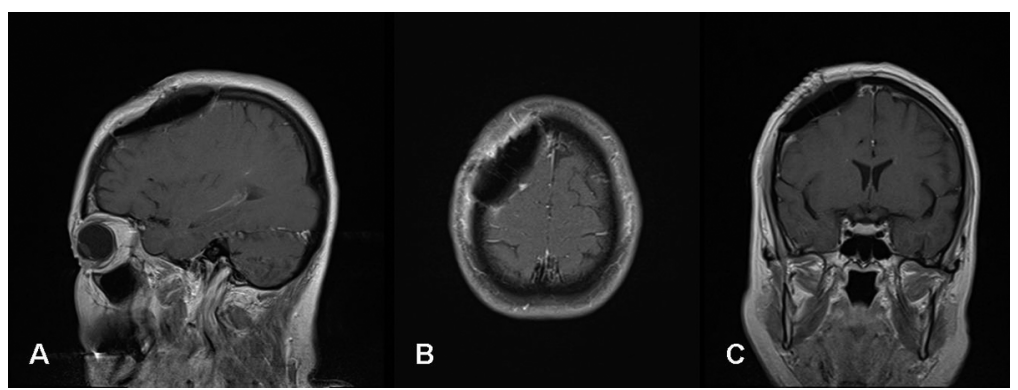


Figure 5. Hematoxylin and eosin-stained sections show abundant histiocytic infiltrate present in sheets with multinucleated giant cells and lymphocytes (A) through a background of fibrous septae (B). Note the presence of multinucleated giant cells (C, arrows). CD 68 stain was used to stain histiocytes (D). Original magnification, $400 \times$.

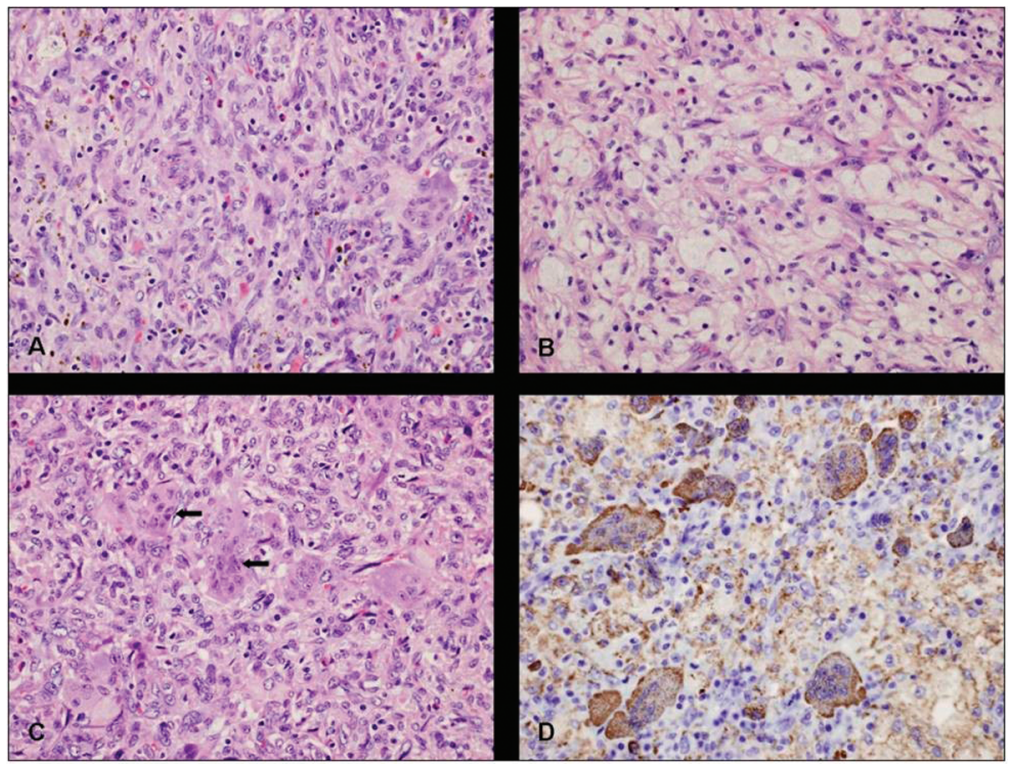

primary bone tumors and $20 \%$ of all benign bone tumors, $5 \%$ to $10 \%$ of which are malignant. ${ }^{7} \mathrm{Al}-$ though controversial, skull-based giant cell tumors are occasionally treated with postoperative radiation therapy. ${ }^{3,14}$

\section{Conclusion}

Our patient presented with what was thought to be a benign subcutaneous skull mass, which, after further assessment, was found to be associated with an underlying osteolytic bone tumor. Osteolytic skull tumors are uncommon and are more often metastatic than benign. Benign lesions can be locally aggressive, so definitive surgical excision typically is recommended when possible. Such excision also provides a tissue diagnosis, which is essential to guide further patient management.

\section{References}

1. Dahlin DC, Unni KK. Bone Tumors: General Aspects and Data on 8,542 Cases. 4th ed. Springfield, IL: Thomas; 1986:12-3.

2. Bitoh S, Takimoto N, Nakagawa H, Namba J, Sakaki S, Gohma T. Giant cell tumor of the skull. Surg Neurol 1978;9:185-8.

3. Pai SB, Lalitha RM, Prasad K, Rao SG, Harish K. Giant cell tumor of the temporal bone- a case report. BMC Ear Nose Throat Disord 2005;5:8.
4. Baldwin HE, Berck CM, Lynfield YL. Subcutaneous nodules of the scalp: preoperative management. J Am Acad Dermatol 1991;25:819-30.

5. Cummings TJ, George TM, Fuchs HE, McLendon RE. The pathology of extracranial scalp and skull masses in young children. Clin Neuropathol 2004; 23(1):34-43.

6. Ramirez AR, Stanton RP. Aneurysmal bone cyst in 29 children. J Pediatr Orthop 2002;22:533-9.

7. O'Donnell RJ, Springfield DS, Motwani HK, Ready JE, Gebhardt MC, Mankin HJ. Recurrence of giantcell tumors of the long bones after curettage and packing with cement. J Bone Joint Surg Am 1994; 76:1827-33.

8. Azouz EM, Saigal G, Rodriguez MM, Podda A. Langerhans' cell histiocytosis: pathology, imaging and treatment of skeletal involvement. Pediatr Radiol 2005;35:103-15.

9. Moon KS, Jung S, Lee JH, et al. Benign osteoblastoma of the occipital bone: case report and literature review. Neuropathology 2006;26(2):141-6.

10. Van der Woude HJ, Smithuis R. Bone tumorsosteolytic-ill defined. Available at: http://www. radiologyassistant.nl/en/4bc99b494a9bd. Accessed 25 September 2011.

11. Skim YS, Ahn JY, Cho JH, Lee KS. Solitary skull metastasis as initial manifestation of hepatocellular carcinoma. World J Surg Oncol 2008;6:66.

12. Leonard J, Gökden M, Kyriakos M, Derdeyn CP, Rich KM. Malignant giant-cell tumor of the parietal 
bone: case report and review of the literature. Neurosurgery 2001;48(2):424-9.

13. Saw S, Thomas N, Gleeson MJ, Bódi I, Connor S, Hortobágyi T. Giant cell tumour and central giant cell reparative granuloma of the skull: do these rep- resent ends of a spectrum? A case report and literature review. Pathol Oncol Res 2009;15(2):291-5.

14. Bertoni F, Unni KK, Beabout JW, Ebersold MJ. Giant cell tumor of the skull. Cancer 1992;70(5): 1124-32. 